\title{
Bioelectricity Generation and Sulfamonomethoxine Removal in Microbial Fuel Cells
}

\author{
Jin Jiang ${ }^{1,2}$, Hui $\mathrm{Wu}^{1}$, Xiaohong $\mathrm{Liu}^{1}$, Kai Sun ${ }^{1}$, Youbin Si ${ }^{1, *}$ \\ ${ }^{1}$ Anhui Province Key Laboratory of Farmland Ecological Conservation and Pollution Prevention, \\ School of Resources and Environment, Anhui Agricultural University, 130 Chang jiang West Road, \\ Hefei, 230036, Anhui, China \\ ${ }^{2}$ College of Electronic and Information Engineering, Anhui Jian Zhu University, Anhui 230061, China \\ *E-mail: youbinsi@ahau.edu.cn
}

doi: $10.20964 / 2020.10 .18$

Received: 2 June 2020 / Accepted: 19 July 2020 / Published: 31 August 2020

\begin{abstract}
Simultaneous electricity generation and sulfamonomethoxine (SMM) wastewater treatment were investigated using a system of dual-chamber Microbial fuel cells (MFCs). SMM is one of the most common contaminants in some rivers and ground wastewater. Shewanella putrefaciens served as a model electroactive bacterium. In this work, the effect of four different substrates on the generation of bioelectricity with two-chamber MFCs based on nafion. 117. CV curve, power density, polarization curve, zeta potential and biofilm enrichment were determined on the anode carbon felt for Shewanella putrefaciens in these MFCs and at the studied SMM concentration range of 10-30 mg/L. The results showed that maximum output voltage and power density obtained from four carbon sources ranged from 296.26 to $899.17 \mathrm{mV}$ and 15.88 to $157.57 \mathrm{~mW} / \mathrm{m}^{2}$, respectively, Zeta potential and Protein concentration obtained from four carbon sources ranged from -3.07 to $-20.87 \mathrm{mV}$ and 5.69 to $15.76 \mu \mathrm{g} / \mathrm{cm}^{2}$. With 10 $\mathrm{mg} / \mathrm{L} \mathrm{SMM}$, the highest degradation rates were $60.08 \%, 58.21 \%, 49.77 \%$, and $31.42 \%$. Relative to other substrates, the most electricity and the least internal resistance was produced using a sodium lactate substrate; also, sodium lactate obtained the highest SMM removal rate. These results indicate that wastewater contaminated with poisonous and refractory organic compounds such as antibiotics could serve as appropriate resources for power generation and contaminant removal using MFC technology.
\end{abstract}

Keywords: Microbial fuel cells (MFCs); Substrate; Power generation

\section{$\underline{\text { FULL TEXT }}$}

(C) 2020 The Authors. Published by ESG (www.electrochemsci.org). This article is an open access article distributed under the terms and conditions of the Creative Commons Attribution license (http://creativecommons.org/licenses/by/4.0/). 